\title{
EL REGENERACIONISMO DE LOS REPUBLICANOS FEDERALES.
}

\author{
GLICERIO SANCHEZ RECIO \\ Universidad de Alicante.
}

«Regeneracionismo» y "desastre del 98» son dos conceptos que se han presentado como íntimamente relacionados, de manera que el primero fuera consecuencia del segundo y éste, el revulsivo de aquel; de ahi la difusión de los términos «generación del 98» e, incluso, «gobierno regeneracionista del 1899» .

Sin embargo, esos dos conceptos deben someterse a un riguroso análisis y este trabajo pretende ser una aportación en ese sentido.

En primer lugar, el regeneracionismo, como ideario y planteamiento político, contaba ya con casi dos décadas de existencia. Varela Ortega ha expuesto ampliamente los objetivos de los trigueros castellanos, los medios políticos a utilizar y su absorción final por los partidos del sistema de la Restauración ${ }^{2}$.

Por otra parte, a lo largo de la década de los años noventa del siglo pasado, habian aparecido una serie de obras que continuaban la ya, en otras épocas, abundante producción de los «arbitristas». Los autores más representativos fueron L. Mallada, M. Picavea, V. Almirall y J. Costa ${ }^{3}$. Este último es el más significativo porque sus planteamientos tuvieron una base intelectual más profunda, partiendo, incluso, de los estudios de derecho consuetudinario, dentro de la escuela histórica

TUÑON DE LARA, M.: Costa y Unamuno en la crisis de fin de siglo. Pags. 26-45. Madrid 1974.

FERNANDEZ ALMAGRO, M.: Historia política de la España contemporánea. 1897-1902 (Vol. III). Págs. 223-229. Madrid 1970.

2 VARELA ORTEGA, J.: «El proteccionismo de los trigueros castellanos y la naturaleza del poder político en la Restauración» en Cuadernos económicos de I.C.E. No 6. Pags. 17, 39-40. Madrid 1978.

${ }^{3}$ MALLADA, L.: Los males de la patria y la futura revolución española. Selección, prólogo y notas de Francisco J. Flores Arroyuelo. Madrid 1969. La obra se habia publicado en 1890.

MACIAS PICAVEA, R.: El problema nacional. Hechos, causas y remedios. Introducción, enlace y notas de Fermin Solana. Madrid 1972. Se habia publicado en 1899.

ALMIRALL, V.: España tal como es. (La España de la Restauración). Prólogo de A. Jutgrar. Madrid 1972. Se habia publicado en 1886.

COSTA, J.: Colectivismo agrario en España. Doctrinas y hechos, Introducción y edición de C. Serrano. Zaragoza 1983. Esta obra se habia publicado en 1898.

- Oligarquia y caciquismo como forma actual de gobierno en España. Urgencia y modo de cambiarla. Introducción de Alfonso Ortí. Madrid 1975. Publicada en 1902.

- Oligarquia y caciquismo. Colectivismo agrario y otros escritos. (Antología). Edición y prologo de R. Pérez de la Dehesa. Madrid 1969. 
del derecho ${ }^{4}$, tratando de los métodos nuevos de la educación desde sus experiencias en la Institución Libre de Enseñanza, llegando hasta los problemas y los intereses de los campesinos del Alto Aragón, y apuntando a la formación de un partido político, que asumiera sus ideas y potenciara su práctica. Muy relacionado con este grupo estuvieron los escritores de la después llamada "generación del 98». Especial mención hay que hacer de Baroja, Maeztu y Azorín por ser quienes más se definieron ante los problemas de España, enumerando, incluso, una serie de medidas adecuadas para superarlos. Azorín, además, era una persona especialmente dotada para captar el contenido y la urgencia de la regeneración por su simultánea relación con Costa y con Pi y Margall ${ }^{4: k}$.

En tercer lugar, este movimiento se dará durante la profunda crisis de finales de siglo, en la que junto a los problemas financieros ${ }^{5}$ aparecen los de la industria y el comercio ${ }^{6}$ y la grave situación por la que pasaba la agricultura?. Es, precisamente, dentro de esta crisis econó-

${ }^{4}$ TUÑON DE LARA, M.: O. C. Pag. 90.

COSTA, J.: Oligarquía y caciquismo. Colectivismo agrario... Edición y prólogo de R. Pérez de la Dehesa. Pag. 10.

PEREZ DE LA DEHESA, R.: Política y sociedad en el primer Unamuno (1894-1904). Pags. 93-99 Madrid 1966. Se refiere al tema cuando trata de las relaciones de Costa con otros hombres de la "Generación del 98".

En el caso del País Valenciano se cuenta con la obra de Rafael Altamira «Derecho consuetudinario y economía popular de la provincia de alicante», que se publicó en 1905. Reeditaba en 1985, en Alicante, con introducción de A. Gil Olcina. RUIZ TORRES, P.: «Economía campesina y capitalismo agrario en el País Valenciano a finales del siglo XIX» en Estudios sobre historia de España (Homenaje a Tuñón de Lara). tomo I. Pags. 203-227. Madrid 1981.

4 his TUÑON DE LARA, M.: O.C. Págs. 139-153.

PEREZ DE LA DEHESA, R.: O.C. Págs. 97 y 126. Azorin, en 1902, en La Voluntad, después de reflejar un cierto deșánimo al tratar de la necesaria regeneración, escribía: "Esto es irremediable, 'Azorín, si no se cambia todo... Los unos son escépticos, los otros perversos... y así caminamos, pobres, miserables, sin vislumbres de bonan. za... arruinada la industria, malvendiendo sus tierras los labradores...» Edición de 1913. Editorial Renacimiento. Madrid.

5 TORTELLA, G. Y OTROS: La banca española durante la restauración. 2 vol. Madrid 1974.

${ }^{6}$ NADAL, J.: El fracaso de la revolución industrial en España. 1814-1913. Barcelona 1975

SARDA, J.: Politica monetaria y fluctuaciones de la economía española en el siglo XIX. Págs. 316-322. Barcelona 1970.

PRADOS, L. y TORTELLA, G.: Tendencias a largo del comercio exterior español (1714-1913). En Revista de Historia Económica. № 2. Pags. 353 y ss. Madrid 1983.

7 GARRABOU, R.: "La crisis agrária española de finales del segle XIX: Una etapa del desenvolupament del capitalisme». Recerques, n. 5. Págs. 163-216. Barcelona 1975.

CARNERO ARBAT, T.: Expansión vinícola y atraso agrario. 1870-1900. Madrid 1980.

AROSTEGUI, J.: Miseria y conciencia del campesino castellano (Memoria acerca de la información agraria en ambas Castillas). Introducción, notas y comentarios de textos por... Madrid 1977. 
mica donde hallarán sentido las aportaciones de los regeneracionistas, a falta de un planteamiento dirigido a la renovación de las estructuras del país. De este modo, el «desastre del 98» no supondría la consumación de la decadencia española sino que más bien habría sido la consecuencia de una "política cubana» equivocada, elaborada de espaldas a la realidad, que menospreció los sentimientos e intereses de los indígenas y de los criollos y minusvaloró el poderío norteamericano ${ }^{8}$, inflamando, en cambio, los sentimientos patrióticos de los españoles, pero, olvidándose de la falta de poder efectivo para mantener las colonias ${ }^{9}$.

Tampoco el regeneracionismo consistió en la asimilación de la anterior decadencia y en la adopción de medidas para superarla, aunque coyunturalmente fuera presentado de esta forma por el «partido de turno») (la Unión Conservadora de Silvela), para privar de los elementos renovadores y del futuro político al movimiento que había comenzado con la asamblea de la Cámara Agrícola del Alto Aragón. De ahí que el calificativo «regeneracionista» se aplique a lo largo del primer tercio del siglo $\mathrm{XX}$ a políticos de signo distinto y se asimile, en ocasiones, a la idea de «revolución desde arriba» ${ }^{10}$.

\section{EL PROGRAMA REGENERACIONISTA DE J. COSTA.}

No se expondrá aquí ampliamente el pensamiento de Costa, tarea

${ }^{8}$ Una de las escasas excepciones en el tratamiento del tema por la prensa española fue precisamente la de F. Pi y Margall expresada en El Nuevo Régimen. Semanario Federal. Ver los artículos: «Mi opinión» del 23 de enero de 1897. «Discurso pronunciado en el Centro Federal» del 17 de julio de 1897. "Las constituciones coloniales» del 4 de diciembre de 1897. "Cuba» del 8 de enero de 1898 "La guerra» del 14 de mayo de 1898.

FORNER, Ph. S.: La guerra hispano-cubana-americana y el nacimiento del imperialismo americano. 1895-1902. 2 vols. Madrid 1972.

JOVER, J.M.: "Caracteres de la política exterior de España en el siglo XIX» en Política, Diplomacia y Humanismo popular en la España del siglo XIX. Págs. 83-138. Madrid 1976.

TORRE, R. de la: «El noventa y ocho español». En Siglo XX Historia Universal 1 (Historia 16). Pags 79-90. Madrid 1983.

${ }_{9} \mathrm{Ph}$. S. Forner y R. de la Torre en la obra (vol. 1) y artículo citado apuntan algunas ideas tendentes a la revisión de este tema. Según R. de la Torre el gobierno español era consciente de su debilidad y el procedimiento elegido para su liquidación respondería a la urgencia con la que se quería terminar el problema de Cuba, aunque fuera a costa de su pérdida.

${ }^{10}$ CARR, R.: España. 1808-1939. Págs. 456-480; 552-558. Barcelona 1970.

TIERNO GALVAN, E.: Costa y el regeneracionismo. Barcelona 1961.

MAURICE, J. y SERRANO, C.: J. Costa: Crisis de la Restauración y el populismo (1875-1911). Madrid 1977. 
realizada con acierto por otros autores desde distintos puntos de vista ". Partiremos de un texto publicado en 1901 en el que aparecen sistematizados los distintos elementos para constituir «el programa del partido nacional», cuyo fin último sería realizar la revolución desde el poder ${ }^{12}$.

El programa, presentado de forma altisonante y apocalíptica, atribuye al partido las funciones de «... Llevar a cabo una total refundición del Estado Español sobre el patrón europeo que nos ha dado hecho la historia y a cuyo empuje hemos sucumbido; restablecer el crédito de nuestra nación ante el mundo... Fundar improvisadamente en la península una España nueva, es decir, una España rica y que coma, una España culta y que piense, una España libre y que gobierne, una España fuerte y que venza, una España, en fin, contemporánea de la humanidad... Tal es la magna... revolución que se impone... Y no pasemos en breve plazo de clase inferior a raza inferior, esto es vasallos que venimos siendo de una oligarquia indígena a colonos que hemos principiado a ser de franceses, ingleses y alemanes» ${ }^{13}$.

A continuación J. Costa enumera doce puntos a través de los cuales piensa que es posible realizar dicha revolución desde arriba ${ }^{14}$ :

1) Transformación del presupuesto del Estado, reduciendo el «de la España muerta o jubilada» y, por consiguiente, aumentando el «de la España naciente, de la España del porvenir». Creando, como medio para llevar a cabo la «nueva orientación política-financiera», «una caja especial autónoma o de varias, independientes del Ministerio de Hacienda, a cargo de cuerpos técnicos, para todos aquellos servicios e instituciones que significan adelanto y enriquecimiento de la nación». El presupuesto de la caja debe ser "la mitad siquiera de todo el presupuesto de ingresos».

2) El medio fundamental para crear la «España del porvenir» es la reforma de la educación. J. Costa comtempla no sólo el plan educativo; de acuerdo con el método de la pedagogía moderna, que atiende a la persona integral, sino también lo que es pevio, «la reforma de las instituciones docentes», mejorar y aumentar el número de escuelas, me-

"MAURICE, J. y SERRANO, C.: O. C., pag. 236. Hay una lista bibliográfica de estudios sobre el pensamiento de $\mathrm{J}$. Costa.

FERNANDEZ CLEMENTE, E.: Educación y revolución en J. Costa. Madrid 1969.

SABORIT, A.: Joaquin Costa y el Socialismo. Madrid 1970.

${ }^{12}$ COSTA, J.: Oligarquia y caciquismo... Edición y prólogo de R. Pérez de la Dehesa. Pags. 38-45.

-- Oligarquía y caciquismo.... Introducción de Alfonso Ortí. Pags. 236-243.

TUÑON DE LARA, M.: O.C. Págs. 92-98

${ }^{13}$ COSTA, J.: Oligarquía y caciquismo... Edición y prólogo de R. Pérez de la Dehesa. Pag. 38.

${ }^{14}$ Ver Nota 12. 
jorar y aumentar el número de maestros y elevar el nivel social de éstos. Habla, incluso, de un sistema de educación permanente. Trata de la destrucción de la vieja universidad, «fábrica de licenciados y proletarios de levita" y de la edificación de la nueva, "cultivadora seria de la ciencia, despertadora de las energías individuales, promovedora de las invenciones»; y potencia los estudios de los españoles en el extranjero. Termina refiriéndose a las experiencias de los norteamericanos en $\mathrm{Cu}$ ba y Puerto Rico y de las de Italia y Japón, paises que habian entrado con gran dinamicidad en el mundo moderno.

3) El abaratamiento de los artículos de primera necesidad mediante el aumento de la productividad, poniendo en práctica el plan hidráulico y la creación de instituciones docentes \{escuelas de Capataces y Gañanes), en donde se expongan y experimenten las técnicas de la agricultura moderna, y mediante la reforma y generalización de las instituciones financieras y del crédito agrícola, «a fin, todo, de que el labrador disponga del capital necesario para la transformación de los cultivos, remover tierras, arrancar viñas, comprar abonos, adquirir ganado». Todos estos medios no implicarán la desaparición de otros habituales para la reducción de los precios: supresión de impuestos, revisión de las tarifas, etc.

4) Facilitar la circulación por el interior del país «a la producción nacional», mejorando y aumentando el recorrido de los "caminos de herradura», con preferencia a «la construcción de carreteras».

5) «Suministro de tierra cultivable, con calidad de posesión perpetua y de inalienable, a los que la trabajan y no la tienen propia», mediante «la derogación de las leyes desamortizadoras en cuanto afectan a los concejos, y autorización a los ayuntamientos para adquirir nuevas tierras... con destino a repartirlas periódicamente al vecindario", la construcción de pantanos, acequias y uartefactos hidráulicos y arados de desfonde a vapor, para servicio de todos. "Apunta también la constitución de los «huertos comunales» y la «ley de expropiación forzosa por causa de la utilidad pública, como en Inglaterra». Para concluir diciendo: «Donde eso no baste, expropiación y arrendamiento o acensuamiento de tierras por el sistema de Floridablanca, Campomanes, de la Novísima Recopilación y de Flórez Estrada ${ }^{15}$.

${ }^{15}$ A estos proyectos se refiere J. Costa en Colectivismo agrario en España, edición de R. Pérez de la Dehesa, Págs. 53 y ss.: Existe también una relación entre los planteamientos de Flórez Estrada y Pi y Margall: Ver SANCHEZ RECIO, G.: «Los planteamientos socioeconómicos del partido democrático. La polémica entre Pi y Margall y Castelar en 1864» en Saitabi, Revista de la Facultad de filosofia y Letras de la Universidad de Valencia, N. XXVII, Págs. 123-144. 1977. Por otra parte, J. Fontana critica los planteamientos de Flórez Estrada. Ver FONTANA, J.: Cambio económico y actitudes políticas en la España del siglo XIX. Págs. 169-170. Barcelona 1973. 
6) Nueva legislación social: regulación del contrato de trabajo, seguro social o popular y socorro mutuo «por iniciativa y bajo la dirección del Estado», cajas de retiro para ancianos y de viudedad y horfandad, inspección del trabajo de las mujeres y de los niños, etc. ${ }^{16}$.

7) «Restablecer el crédito monetario de la nación... mediante la europeización de la agricultura, de la minería y del comercio, ... de la administración pública y de la política...».

8) Creación de un «poder judicial digno de su función» mediante el «expurgo», la reeducación del p̉ersonal existente, y «la formación de otro nuevo, que responda a las necesidades de la nueva situación y a los ideales del nuevo Estado».

9) Autonomía municipal, «régimen de los municipios por ordenanzas locales, de formación obligatoria, reformablès anualmente e intervenidas por el gobierno». "Generalización del sistema de consejo o democracia directa... o, en su defecto, del referendum». "Municipalización de los servicios públicos», y de creación por los municipios «de ciertas industrias o comercios en concepto de regulación o como monopolio». "Separar en absoluto la administración local de todo lo que sea política general de la nación, desaparición de las Diputaciones provinciales y creación de «organismos más amplios».

10) Sustitución del «liberalismo abstracto y legalista imperante, que ha mirado no más a crear y garantizar las libertades públicas» por un «neoliberalismo orgánico, ético y sustantivo, que atienda a crear y afianzar dichas libertades con actos personales de los gobernantes».

11) La ejecución de las anteriores ideas ha de realizarse de manera inmediata y simultánea, «porque son orgánicas entre si y cada una de ellas supone a las demás», forzosamente y por trámite sumarísimo, para superar el atraso, y por decreto «huyendo los procedimientos dilatorios y la sistemática obstrucción de las Cortes...»

12) Finalmente, renovar el personal político que llegó al poder con la Restauración, incluida «la representación actual del poder moderador» y formar "órganos nuevos» de opinión y de gobierno, con hombres aptos» para encarnar el presente minuto de nuestra patria y vencer su crisis, realizar el precedente plan de revolución y reprimir instantáneamente...».

Ante este programa de $\mathrm{J}$. Costa son muchos los problemas que

${ }^{16}$ Nuevos proyectos de legislación social estaban siendo elaborados por la Comisión de Obras Sociales, uno de los cuales, el de accidentes de trabajo, se convertía en ley en 1900. La previsión social se estaba llevando a cabo mediante asociaciones particulares. Ver HERNANDEZ FERRIS, R.: La Sociedad Cooperativa "EI Trabajo». 1880-1942. Memoria de Licenciatura, inédita. Facultad de Filosofia y Letras de la Universidad de Alicante. 1984. 
pueden plantearse: En primer lugar, es interesante destacar el esquema de razonamiento y exposición que utiliza. Se trata de una lucha de contrarios, que no aspira a un tercer elemento de síntesis, sino que se resuelve en sí misma con la imposición de uno sobre otro ${ }^{17}$, y del uso continuo de conceptos filosóficos y biológicos, símbolos y términos de carácter muy general y con una gran carga efectista como son los de "africanización-europeización», "Santiago de Cuba-Santiago de Galicia», «España muerta y jubilada-España naciente y del porvenir», «liberalismo abstracto y legalista-neoliberalismo orgánico, ético y sustantivo", etc., por los que si no consigue exponer con claridad sus ideas, si logra captar la atención del lector y del oyente y que se interese por su pograma.

Posteriormente, el significado del concepto de revolución, que él especifica y contrapone como «Revolución desde arriba» frente a la «revolución desde abajo» ${ }^{18}$. La "revolución desde arriba» tendría por objetivo la aplicación del anterior programa moderno y reformista; en cambio, la «revolución desde abajo», concepto que J. Costa no explica, llevaría consigo un efecto perturbador y destructivo de la sociedad ${ }^{19}$. La idea de la revolución en Costa está muy lejos de la revolución «orgánica» y se queda más próxima a la de revolución «política », que supone un simple cambio del equipo que ejerce el poder y en la aplicación de unas determinadas reformas ${ }^{20}$.

Las reformas previstas en el programa son eminentemente técnicas e implican una importante intervención del «nuevo Estado». Entre ellas son de destacar: a) La reforma de la educación y la función que se le concede en el proceso de transformación de la sociedad española, asuntos que Costa conocia pefectamente por su dilatada experiencia en la Institución Libre de Enseñanza ${ }^{21}$.

${ }^{17}$ Es éste un esquema dialéctico semejante al utilizado por Proudhon en sus obras. Ver SANCHEZ RECIO, G.: «La influencia de los pensadores y de los traductores franceses en F. Pi y Margallı. Anales de la Universidad de Alicante. Historia Contemporánea. N. 2, págs. 135-157. 1983.

18 TUÑNON DE LARA, M.: O.C. Pag. 97.

${ }^{19}$ El concepto de socialismo utilizado aquí por J. Costa, además de muy impreciso, es el adoptado por la burguesía en las décadas centrales del siglo XIX, aunque tampoco puede olvidarse del radicalismo de las organizaciones anarquistas en los años noventa del pasado siglo: MALUQUER DE MOTES, J.: El socialismo en España. 1883-1868. Barcelona 1977.

TUÑON DE LARA, M.: El movimiento obrero en la historia de España. Barcelona 1977 (Edic. Laia).

SABORIT, A.: O. C. Págs. 99 y ss.

${ }^{20}$ FONTANA, J.: O. C. Págs. 99-106.

${ }^{21}$ FERNANDEZ CLEMENTE, E.: O. C. Págs. 55 y ss..

GOMEZ MOLLEDA, Ma D.: Los reformadores de la España Contemporánea. Madrid 1966. 
b) Su preocupación e interés por el campesinado (pequeños propietarios y agricultores sin tierra); de ahí que arbitre varios medios para el acceso a la «posesión» de la tierra de los campesinos que no la tienen, para el cultivo de la misma y para el aumento de la productividad. Trata muy por encima de la expropiación forzosa, por lo que la estructura agraria permanecería inalterada.

c) La disponibilidad y la facilidad del crédito y una correcta aplicación del presupuesto a las necesidades reales de la nación.

d) Existe un cuarto elemento por omisión, la ausencia de cualquier referencia a la industria, a los grupos sociales y a los intereses con ella relacionados ${ }^{22}$.

Para llevar a cabo este programa había de ser previa la toma del poder, establecer las reformas políticas necesarias $y$, finalmente, se encomendaría la vigilancia de la correcta aplicación de las mismas a un «poder judicial digno de su función».

Sin embargo, lo anterior nos lleva a plantearnos un doble problema: La creación del medio adecuado para llegar a la toma del poder $y$, en segundo lugar, la naturaleza del poder político. Costa intenta conseguir lo primero mediante la constitución de un partido nacional, para lo cual pretende utilizar como base la Cámara Agricola del Alto Aragón, reunida en asamblea en noviembre de 1898, que lanzó un manifiesto el día 13, en el que aparecían las ideas del anterior programa; en febrero de 1899 se celebró en Zaragoza la Asamblea Nacional de productores, en la que participaron las Camaras Agricolas, las de Comercio e Industria, los Círculos Mercantiles, etc., de la que salió la liga $\mathrm{Na-}$ cional de Productores, con un programa mínimo para influir sobre el gobierno del Estado, abandonándose los anteriores planteamientos de partido. Finalmente, en 1901 se desintegraba este movimiento, entrando la mayoría de sus jefes en los partidos de turno ${ }^{23}$.

En cuanto a la naturaleza del poder político, es decir, a la concepción del Estado, el pensamiento de J. Costa es mucho menos preciso. Sólo habla del «neoliberalismo orgánico, ético y sustantivo», que permitirá una gran libertad de acción a los gobernantes, y de la expurgación del personal político que habia ejercido el poder desde el principio de la Restauración. Sin embargo, aquí se abren una serie de interro-

${ }^{22}$ TUÑ் DE LARA, M.: O. C. Págs. 97.

"La asamblea de produtores» en El Nuevo Régimen, 18 de febrero de 1899. A pesar de que el artículo no está firmado puede deducirse que pertenece a $\mathrm{Pi}$ y Margall por su estilo y por las ideas contenidas.

${ }^{23}$ CHEYNE, G.J.G.: Joaquín Costa, el gran desconocido. Págs. 131-142. BarceIona 1971.

TUÑON DE LARA, M.: O. C. Págs 186-206. 
gantes sobre la estructura y los poderes del Estado, el sistema de representación, etc., de los que J. Costa no trata ${ }^{24}$.

\section{LOS PLANTEAMIENTOS REGENERACIONISTAS DE PARTIDO REPUBLICANO FEDERAL.}

Los proyectos de regeneración no fueron exclusivos de un grupo de intelectuales y del programa de un partido nonato, sino que salpicaron también a los de los partidos del turno y a los de la oposición, y, más aún, en un momento en el que el cambio se hacía necesario, una vez quemado el gobierno de Sagasta por el resultado de la guerra de Cuba. De nuevo se presentaba la hora del partido conservador, que, ademas, tenía que resolver el problema de su dirección por haber desaparecido Cánovas. Es en esta coyuntura cuando se alza la voz de Silve$\mathrm{la}^{25}$, quien consigue ser aceptado como jefe del partido y aglutinar en torno a él a las personas más destacadas del mismo ${ }^{26}$, quienes en marzo de 1899 formaban el gobierno y convocaban posteriormente las elecciones, en las que obtendrian una amplia mayoría que les permitiría gobernar cómodamente. Este gobierno elaboró los primeros proyectos reformistas, el principal de todos ellos fue el de ajustar el presupuesto, a cargo de Villaverde, ministro de Hacienda ${ }^{27}$. También la oposición aprovechó la conyuntura para exponer su ideario, sus programas de reformas y presionar sobre el gobierno.

El partido republicano federal planteó sus intervenciones en una doble dirección política: una, de tipo didáctico y propagandístico, en reuniones, actos y mítines organizados por el propio partido, y otra, de carácter parlamentario, a través de sus miembros en el Congreso de los Diputados. Aqui estudiaremos los discursos pronunciados, en uno y otro casos, por el jefe del partido, F. Pi y Margall, y otros escritos publicados en El Nuevo Régimen entre 1898 y $1901^{\text {28. }}$. En los primeros se exponían los principios programáticos del partido, entre los que se incluia un amplio plan de reformas, similares a las propuestas por la Cá-

${ }^{24}$ Escribe Tuñón de Lara: «El gran vacio costiano fue siempre la cuestión del po der» (lb. pag. 98).

${ }^{25}$ TUNON DE LARA, M.: O. C. Pág. 69

FERNANDEZ ALMAGRO, M.: O. C. Págs. 208-215.

${ }^{26}$ FERNANDEZ ALMAGRO, M.: O. C. Págs. 219-226.

27 FERNANDEZ ALMAGRO, M.: O. C. Pág. 223.

TORTELLA, G. Y OTROS: La banca española durante la Restauración. Vol. I. Págs. 172-177.

VARIOS: El banco de España. Una historia económica. Págs. 295-297. Madrid 1970.

${ }^{28}$ El Nuevo Régimen. Semanario Federal. Madrid. El número 1. se publicó el 17 de enero de 1891. Semanario ligado estrechamente a la persona de F. Pi y Margall se convirtió en el órgano principal del partido republicano federal. 
gall tocaba el tema del regeneracionismo desde la perspectiva federal. El contenido de la misma puede considerarse como programático de la actividad política que desarrollaría hasta finales de 1901. Trató, en primer lugar, de la estructura federal del Estado, a la que, incluso, fundamentó filosóficamente, según sus principios habituales, y después de repasar las ventajas del sistema federal y de atacar al caciquismo como «sistemático falseamiento de la voluntad del pueblo», expuso su programa para la regeneración de España, enumerando, primero, los males de la patria:

«España es una de las naciones más atrasadas de Europa. Cuenta sólo 18.000.000 de habitantes; cuando Francia...; tiene apegada la agricultura a la rutina y escasamente admitidas las prácticas que hoy hacen de tierras estériles tierras fecundadas. Tiene reducidas la industria a corto número de poblaciones. Es de las que cuenta menos kilómetros de ferrocarril, y en los ferrocarriles menor movimiento de viajeros y de mercancias. Ni aún en vías ordinarias abunda, cuando tantas exige el fácil y barato transporte de nuestros productos para que puedan competir con los que de otras naciones nos vienen. Su escasa cultura, bien claramente la revela el hecho de que no sepa leer ni escribir siquiera el cincuenta por ciento de los españoles».

Ante este cúmulo de males enunciado, ofrece como soluciones «la instrucción y el trabajo», pero ambos elementos están íntimamente relacionados. El problema más grave que arrastraba el país era el de la hacienda pública:

"Vengamos ahora a lo más espinoso, a la Hacienda. Nunca se logra aquí nivelar los presupuestos. Los déficits se cubreri con deuda flotante del tesoro, y la deuda flotante pasa, periódicamente, a ser consolidada ... Cálculese que será ahora si hemos de tomar sobre nosotros la deuda de Cuba, que no bajará de tres mil millones de pesetas».

Ante esta situación sólo cabía una profunda transformación del presupuesto, que implicaba, a la vez, cambios políticos de importancia:

«Si hemos de fomentar la instrucción y el trabajo, hemos de transformar los presupuestos. No es posible que sostengamos ni la actual lista civil ni los sesenta y más millones de las clases pasivas, ni los cuarenta de las obligaciones eclesiásticas. No es posible que dejemos de reducir los capítulos de Guerra y Marina y el de la recaudación de rentas y contribuciones, fácil de rebajar por el sistema que os propongo».

En todas sus intervenciones públicas durante estos años Pi y Margall volvió sobre estos problemas, ampliando la relación de las refor- 
mara Agrícola del Alto Aragón y por la Liga Nacional de Productores, y en los segundos se respondía desde el punto de vista del partido a los proyectos del gobierno ${ }^{29}$.

\section{FEDERALISMO Y REGENERACIONISMO.}

El partido republicano federal a partir de 1874 estuvo formado por un pequeño grupo testimonial, dirigido ideológica y tácticamente por F. Pi y Margall, quién desde 1881 extendió su actividad pública al amparo de la ley de reunión de $1880^{30}$ y estuvo presente en el Congreso de los Diputados en la Legislatura de 1886 y a partir de la de 1891, por la promulgación de la ley del sufragio universal de 1890; sin embargo, el peso real del partido nunca estuvo al nivel de su altura ideológica. No se ha realizado todavía un estudio acerca del partido republicano federal, y no sabemos, por tanto, cual era su base electoral y su aceptación en la sociedad, ni conocemos el origen de los fondos con los que se financiaban sus campañas y sus medios de difusión. La presencia de sus miembros en el Congreso de los Diputados se consiguió desde 1891 a través de la coalición La Unión Republicana. Por otra parte, este pequeño partido republicano tenía perfectamente elaborados sus principios programáticos desde $1894^{31}$.

Respecto al tema que aquí nos ocupa, el regeneracionismo, los republicanos federales fueron conscientes del problema y, de manera semejante a los partidos del turno dinástico, introdujeron el regeneracionismo en su programa, más aún, como la República Federal se presentaba como alternativa del sistema establecido, el programa del partido aparecia como regenerador, sin que esto supusiera ningún cambio significativo en el mismo; de ahí que se hiciera un abundante uso de los términos «regeneración» y «degeneración» en los discursos y escritos.

En una conferencia pronunciada en el Círculo de la Unión Mercantil de Madrid, a finales de $1898^{3 "}$ sobre "la crisis de España», Pi y Mar-

${ }^{29}$ La actividad pública y política de Pi y Margall la hemos tratado más ampliamente en otro lugar: SANCHEZ RECIO, G.: Los discursos politicos de Pi y Margall durante la Restauración. Memoria de Licenciatura, inédita. Facultad de Filosofia y Letras de la Universidad Complutense de Madrid. 1973.

30 SANCHEZ RECIO, G.: "Aportación a la historia politica del País Valenciano. Viaje de propaganda federal de F. Pi y Margall en 1881». Item. Revista de Ciencias Humanas. Centros de Estudios Universitarios de Alicante. № 4, Págs. 95-102. 1978.

${ }^{31}$ En el mes de junio de ese año se celebró una asamblea federal en Zaragoza en donde se aprobó el programa del partido. Ver El Nuevo Régimen, 23 de junio de 1894 y 14 de diciembre de 1901.

PI Y MARGALL y PI Y ARSUAGA: La historia de España en el siglo XIX. Vol, VI. Págs. 892-904. Barcelona 1902.

32 El Nuevo Régimen, 3 de diciembre de 1898. 
mas que convenía realizar ${ }^{33}$. Especial importancia tiene el dicurso pronunciado en el Centro Federal de Madrid, el 4 de noviembre de 1899, dedicado, en su mayor parte, al tema de la instrucción y de la mujer, a través del cual aparecen claramente las ideas de los republicanos federales sobre la política educativa: la instrucción general debe ser común para los dos sexos, las escuelas, mixtas e igualdad total entre el hombre y la mujer; de ahí que juzguen indispensable algunas reformas relativas a la mujer ${ }^{34}$.

\section{LOS REPUBLICANOS FEDERALES FRENTE AL GOBIERNO DE SILVELA.}

El campo elegido para el combate fue el Congreso de los Diputados, en donde los republicanos federales estaban representados por varios diputados. Las ideas defendidas por Pi y Margall han sido expuestas fundamentalmente más arriba, aunque en sus discursos las concretara más y tratara de otras nuevas, aprovechándose de la conyuntura política.

Los republicanos federales fueron a las elecciones tácitamente aliados con los socialistas «aunque no hemos pactado alianza alguna», como diría Estévanez, candidato republicano federal, en el mitin celebra-

${ }^{33}$ Discursos de Pi y Margall en los que trató de las reformas a realizar:

- 7 de enero de 1899 en el Círculo Federal. El Nuevo Régimen, 14 de enero.

- 11 de febrero de 1899 en el Círculo Federal. El Nuevo Régimen, 18 de febrero.

- 1 de abril de 1899 en la Asociación de la Prensa. El Nuevo Régimen, 8 de abril.

- 6 de agosto de 1899 en el Nuevo Teatro. El Nuevo Régimen, 12 de agosto.

- 11 de febrero de 1900 en el Centro Federal. El Nuevo Régimen, 17 de febrero.

- 17 de noviembre en el Centro Federal. El Nuevo Régimen, 24 de noviembre.

- 11 de febrero de 1901 en el Círculo Federal El Nuevo Régimen, 16 de febrero.

${ }^{34}$ El Nuevo Régimen, 11 de noviembre de 1899. Por su importancia reproducimos algunos párrafos: «Para que la enseñanza produzca más resultados, es indispensable a mi juicio, que la instrucción general, lo que hoy comprenden la primera y la segunda enseñanza, sea común a los dos sexos. La mujer, como sabeis, es la que instruye y educa a los niños en los cuatro primeros años de la vida...

«En mi opinión las escuelas deberían ser todas para ambos sexos. No comprendemos que se les separe, cuando unidos podrian las hembras activar la energía intelectual de los varones y dulcificarles los sentimientos...

«A la mujer se le reconoce generalmente inferior al hombre, sin ver que esa inferioridad depende en gran parte de que no se le dé la instrucción que a los varones...

«Así yo entiendo que es indispensable reformar las leyes relativas a la mujer... «Tampoco le hace favor la sociedad. En el trabajo, generalmente hablando, no percibe nunca jornales tan altos como los de los varones, y tiene cerradas las puertas de un gran número de industrias...

«Tampoco goza la mujer de todos los derechos políticos. Se le permite que escriba... No que goce el derecho de sufragio...» 
do el 14 de abril de 1899 en el Círculo Federal, en el que también participó Pi y Margall, cuyo discurso estuvo dedicado en su mayor parte a tratar de las semejanzas programáticas de ambos partidos ${ }^{35}$.

Podría sintetizarse el ideario regeneracionistas de los republicanos federales con unas palabras de Pi y Margall pronunciadas en el Congreso de los Diputados, el 10 de julio de 1899, criticando el programa del gobierno: «Equilibrar los presupuestos no es regenerar la patria: no es abrir carreteras, ni construir ferrocarriles secundarios, ni canalizar los ríos, ni abrir las numerosas escuelas que el pueblo necesita» ${ }^{36}$. Sin embargo, la novedad principal era la de los recursos con los que deberían cubrirse los gastos necesarios para efectuar las anteriores obras: el presupuesto eclesiástico y la mayor parte de los haberes pasivos ${ }^{37}$. Más aún debería realizarse una emisión de papel «por una cantidad cuyos intereses y amortización pudieren cubrirse con lo que hoy importan esas dos secciones del presupuesto».

El programa republicano federal se completaba con la defensa de su sistema político, con el que se resolvía el problema de la descentralización administrativa, de la regionalización del Estado y de la autono-

35 El Nuevo Régimen, 15 de abril de 1899.

${ }^{36}$ El Nuevo Régimen, 15 de julio de 1899. Diario de Sesiones del Congreso de los diputados, 1899-1900; n. 32, pp. 789-792. Otros discursos de Pi y Margall pronunciados en esta legislatura fueron:

- 17 de julio de 1899. El Nuevo Régimen, 22 de julio Diario de Sesiones, N. 32, pp. 1020-1022

- 28 de julio sobre los «sucesos de Barcelona». El nuevo Régimen, 29 de julio de 1899. Diario de Sesiones, № 48, pp. 1446-1448.

-13 de noviembre de 1899. El Nuevo Régimen, 18 de noviembre, Diario de Sesiones, $N^{\circ} 60$, pp. $1817-1820$

- 20 de noviembre de 1899 sobre «los departamentos ministeriales». El Nuevo Régimen, 25 de noviembre Diario de Sesiones, N. 66, pp. 2047-2048

$-20,21$ de diciembre de 1899. El Nuevo Régimen, 23 de diciembre Diario de Sesiones, Nos. 91 y 92 , pp. 2.999-3.000, 3.037-3.038.

-8 de febrero de 1900. El Nuevo Régimen. 10 de febrero Diario de Sesiones. № 45. Extracto de la Gaceta.

-7 de marzo de 1900. El Nuevo Régimen. 10 de marzo Diario de Sesiones, № 144 , pp. 5.034-5.037.

- 12 de diciembre de 1900. El Nuevo Régimen. 15 de diciembre. Diario de Sesiones. 1900-1901. № 19 pp. 456-457.

${ }^{37}$ Decia Pi y Margall al respecto: "La Iglesia no necesita que el Estado la subvencione. Exige recompensa de los servicios que presta..."

«Soy también partidario de la reducción de los haberes pasivos... Nacen esos haberes de ciertos montepíos que se alimentaban con los descuentos de los funcionarios públicos. Desaparecieron los montepíos civiles en el año 1851 y los militares en 1857. Los que desde entonces entraron en la administración no tienen derecho al disfrute de pensión alguna, ya que no contribuyeron ni a la creación ni al mantenimiento de los montepios. Podrán subsistir, cuando más, los haberes de los que entonces estaban al servicio del Estado». 
mía de los pueblos. Desde esta perspectiva llevaría a cabo la defensa de los regionalistas catalanes (discurso del 28 de julio sobre los sucesos de Barcelona) ${ }^{38}$, en reconocimiento de lo cual sería nombrado mantenedor de los Juegos Florales de Barcelona de 1901.

Otro elemento importante del programa era la reforma y reducción del ejército y de la armada, fundándolo sobre la existencia de un pequeño núcleo de militares profesionales y una abundante y bien entrenada reserva (discurso del 17 de julio y del 20 y 21 de diciembre de 1899) ${ }^{*}$. En el primero de estos, muy alejado de la realidad, decía Pi y Margall que partía en su exposición del hecho «de que nos hemos curado totalmente de la manía colonial, después de los resultados de la guerra de Cuba y Filipinas y de la venta a Alemania de las Carolinas, las Marianas y las Palaos ${ }^{40}$. La reforma del ejército y de la armada supondría un importante ahorro en el presupuesto que debía destinarse a las obras de la modernización del pais.

En el mismo sentido exponía sus ideas sobre la reforma de la administración del Estado, partiendo de dos principios:

a) Separación de la política y de la administración: «Al paso que la política corresponde a los ministros, la administración ha de correr a cargo de los directores generales. Los directores generales han de salir siempre del fondo de la administración, jamás de la política, y han de responder en todo caso de sus resoluciones, nunca de los ministros».

b) La reducción del número de los ministros, que simplifica en tres: gobernación -interior, Estado -exterior- y Hacienda ${ }^{41}$.

Finalmente, en el discurso pronunciado el 12 de diciembre de 1900 , Pi y Margall hacía referencia al tema de la instrucción pública, criticando las bases de la reforma del gobierno sobre la enseñanza secundaria, en lugar de construir nuevas escuelas de enseñanza primaria y dotarlas mejor.

Pi y Margall continuó defendiendo estas mismas ideas en la legislatura de $1901^{42}$.

\section{${ }^{38}$ Ver la Nota 36.}

${ }^{39}$ Ver la Nota 36.

40 JOVER, J. Ma: O.C. Págs. 133-138.

GIMENEZ LOPEZ, E.: «Ejército y federalismo. Un proyecto de organización de ejército republicano en 1872». En Item. №. 2. Págs. 111-124. 1977.

${ }^{41}$ Discurso del 20 de noviembre de 1899 «sobre los departamentos ministeriales».

42 Discurso del 15 de julio de 1901. El Nuevo Régimen, 20 de julio. Diario de Sesiones del Congreso de los Diputados. 1901-1902. N. 29 pp. 610-613. 
$D E J$. COSTA.

A través de las páginas de El Nuevo Régimen, estrechamente ligado a la persona de $\mathrm{Pi}$ y Margall, se manifiesta la actitud de los republicanos federales y, particularmente, de su jefe hacia los proyectos reformistas de Costa. Estos no fueron vistos con simpatia por su imprecisión política y por la cortedad de sus perspectivas socioeconómicas y administrativas, aunque en algún momento se pusieran junto a las Cámaras de Comercio en contra del gobierno de Silvela, alegando la «burla» y el no cumplimiento de la palabra dada de llevar a cabo los proyectos de reforma elaborados por aquéllas, a pesar de que no fueran de total agrado para los republicanos federales ${ }^{43}$.

En términos generales, se critica la persona de Costa, aprovechando la actitud mantenida por éste, en la asamblea de Productores de Zaragoza:

«A nuestro modo de ver, el Sr. Costa, verbo de la referida Cámara Agrícola (la del Alto Aragón), va por mal camino. Abomina de los políticos sin distinción y se propone crear un partido; condena lo mucho que se habla en los Parlamentos, y no abre los labios que no pronuncie un discurso largo....»

$Y$ termina el artículo, afirmando:

«Es una verdadera ilusión creer que basta formular proyectos para que el país se regenere. Lo difícil no es concebirlos, sino imponerlos; y para imponerlos no hay más que dos caminos... ${ }^{44}$.

Rechazan también las relaciones del movimiento de las Cámaras y de la Liga con los gobiernos de la nación, primero, el de Sagasta y, después, el de Silvela. Los republicanos federales apoyaron a Sagasta en su no aceptación de las propuestas de las Cámaras de Comercio, acordadas en la Asamblea de Zaragoza, en noviembre de 1898, que se arrogaban una representación al margen del Parlamento, en un artículo equívocamente titulado "La Unión Conservadora» ${ }^{45}$. En cambio, critican la falta de firmeza en el mantenimiento de sus proposiciones frente al gobierno ${ }^{46}$ y la dureza empleada por éste en la represión del movi-

43 «Las Cámaras de Comercio». en El Nuevo Régimen, 25 de noviembre de 1899. Aunque el artículo no está firmado puede deducirse que su autor es Pi y Margall.

44 "La Asamblea de Productores» en El Nuevo Régimen, 18 de febrero de 1899.

${ }^{45}$ El Nuevo Régimen, 14 de enero de 1899. "La unión conservadora fue el nombre bajo el cual concurrió la mayor agrupación del partido conservador en las elecciones de la primavera de 1899, bajo la dirección de Silvela.

${ }^{46}$ El Nuevo Régimen, 25 de noviembre de 1899, artículo citado, y 23 de diciembre, artículo titulado "Las Cámaras y la Liga». 
miento ciudadano (negativa al pago de los impuestos y cierre de las tiendas) para repudiar la actitud del gobierno ${ }^{47}$.

En definitiva desde la órbita de los republicanos federales podría sintetizarse la trayectoria de los proyectos regeneracionistas de las Cámaras de Comercio y de la Liga de Productores con unas palabras de $\mathrm{Pi}$ y Margall, pronunciadas en el Centro Federal de Madrid, el 17 de noviembre de 1900:

"Todos recordareis que después de la pérdida de las colonias hubo en Zaragoza dos asambleas: la de las Cámaras de Comercio y de la Liga de Productores. Las dos propusieron gran número de reformas, y las llevaron al gobierno, a la Regente y a las Cortes. De todos recibieron promesas, pero promesas no cumplidas. Viendo que nada conseguían, recurrieron a medidas un tanto violentas... que el gobierno dominó suspendiendo las garantías constitucionales. Perdió el país la esperanza de mejores días, y de aquí la anemia que en la política observamos» ${ }^{48}$.

47 "Despujols» en El Nuevo Régimen, 25 de noviembre de 1899.

${ }^{48} \mathrm{Ver}$ la nota 33 . Casi estas mismas palabras las pronunciaba de nuevo en el Congreso de los Diputados pocos dias después, el 12 de diciembre (ver la Nota 36). 